肺部提伤程度的变异数分析

\begin{tabular}{|c|c|c|c|c|c|}
\hline \multicolumn{2}{|c|}{ 变异来湍 } & 平方合 & 自由度 & 均 方 & $\mathbf{F}$ \\
\hline 总 变 & 异 & 4.378 & 49 & & \\
\hline 处 & 理 & 0.331 & 4 & 0.083 & 1.08 \\
\hline 鼣 & 差 & 4.047 & 45 & 0.090 & \\
\hline
\end{tabular}

$n_{1}=45, n_{0}=4, P>0.05$, 美异不显著

两平均数之間的显堻差异 $=2.01 \sqrt{\frac{2 \times 0.090}{10}}=0.27$ 处理 租与对照粗之間并無显著差异。

存活日数的变算数分析

\begin{tabular}{|c|c|c|c|c|c|c|}
\hline \multicolumn{3}{|c|}{ 变异来源 } & 平方合 & 自由度 & 均 方 & F \\
\hline 总 & 变 & 异 & 407.62 & 49 & & \\
\hline 处 & & 理 & 29.12 & 4 & 7.280 & 1.16 \\
\hline 触 & . & 整 & 378.50 & 45 & 8.411 & \\
\hline
\end{tabular}

$n_{1}=45, n_{2}=4, P>0.05$, 美异不显著

两平均数之間的显语差异 $=2.01 \sqrt{\frac{2 \times 8.411}{10}}=2.6$ 天

处理祖与对照租之間讲無显著美异。

\section{江西大吉山、盘古山含鵭 石英豚的生长特点}

热液石英脉呈塊状結构为大家所熟知。国內已有 文献[1]中皆認为它盛于原生成因, 且为高温石英脉的 特征。苏联 $\Gamma$. H. 維尔圖什科夫曾于 1946 年研究烏拉 尔無矿石英脉时提出塊状結构系次生的, 抹指出原生 絡构具有柱状特征。但他的这种看法: “塊状結构系后 期抅造破坏所引起的变化及变澌作用的結果”在苏联

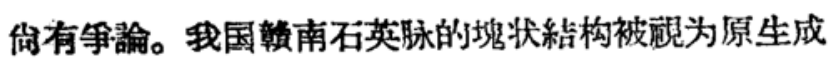
因，但扭未經細研究。作孝在硋区进行了初步覌察 及塑理，特提出下列簡短报导。

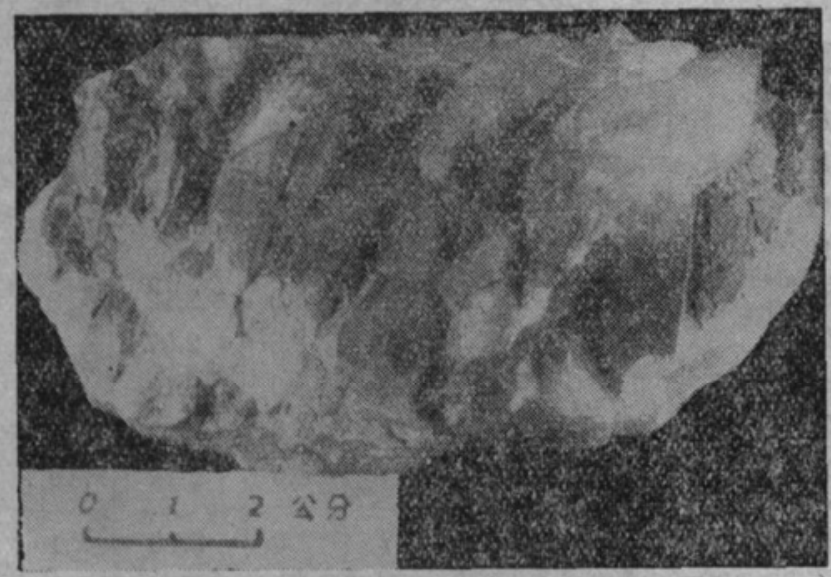

圖 1 晶体生长結束于晶簇生长阶段（盘古山）
一、石英肤的生长特点: 根据野外观然, 确定䠹 区原生生长結构均为按正常方式自由生长, 晶体的生

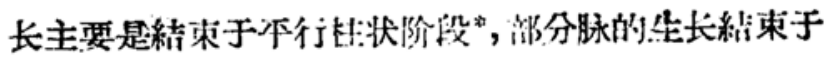

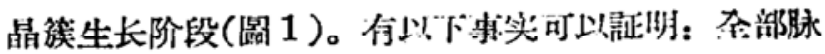
皆为梳状結构所光塔; 或为由誘导品面包国的个体組

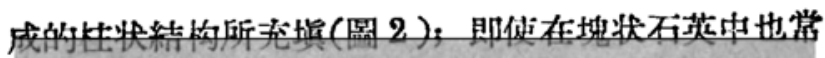

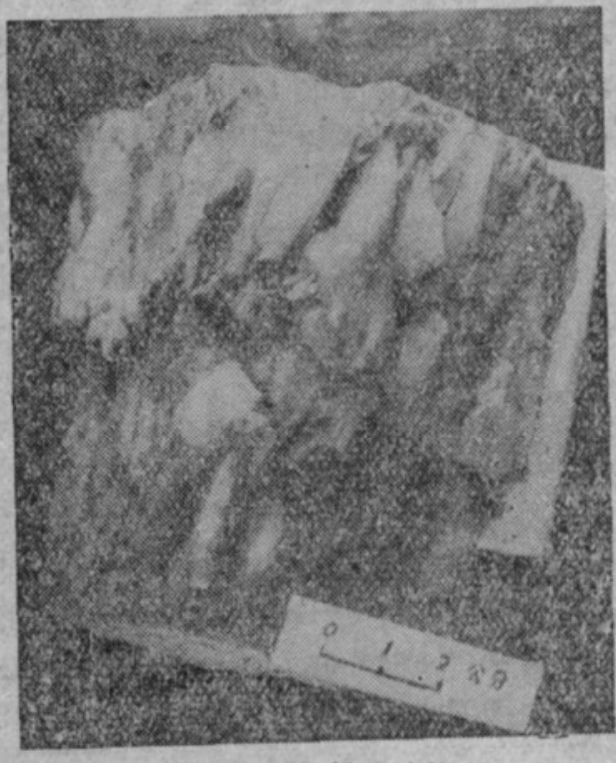

圖 2 平行杜状結构

見作为柱状結构标志的誘导昆面残余, 另外小品润壁

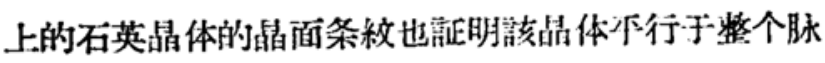
的柱状結构方向。結束于晶籍生长阶段的脉宽度多为 10-20 厘米, 石英个体呈交錯生长, 个別与脉壁交的

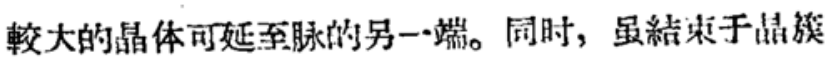
阶段，仍可光滿全脉或在它部留有小空洞。另外本区 的平行柱状結构均表現有明显的几何澡汰現象, 故知 其是在开閶裂縫中結占而成的。

根据誘导晶面的残余叮确定原生性状絃构的个体

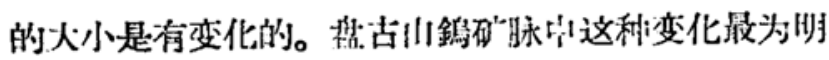
显。主要的影响因素是矿泳筧度及所在深度。一般上 部中段石英䟿寬約 $0.5-0.7$ 米, 其中个体蓝断湎直径約 5-7 厘米。中部肤寬达 1 米, 个体直径为 6-10 厘米。 下部中段主要的矿脉筧达 2.5 米，个体㨁径一般为 10 -15 厘米, 个別可达 20 厘米。以六中段 7 号脉尔矿 場中的伟晶結构的个体最为清哳, 圖 3 即为硋采研“埸 內的由誘导晶面所包围的个体。

二、脉石英的变化現像: 原生的平行柱状結构释 过次生变化颜形成了今日所見的塊状結构。正足这些 变化現象使石英肤的本来面目不易辨認。变化过程可 以分为成矿时及成研“后两个阶段。成矿时的变化主要

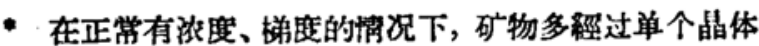
生长阶段, 晶筷生长阶段及平行柱状生长阶段而完成 其結晶作用。 


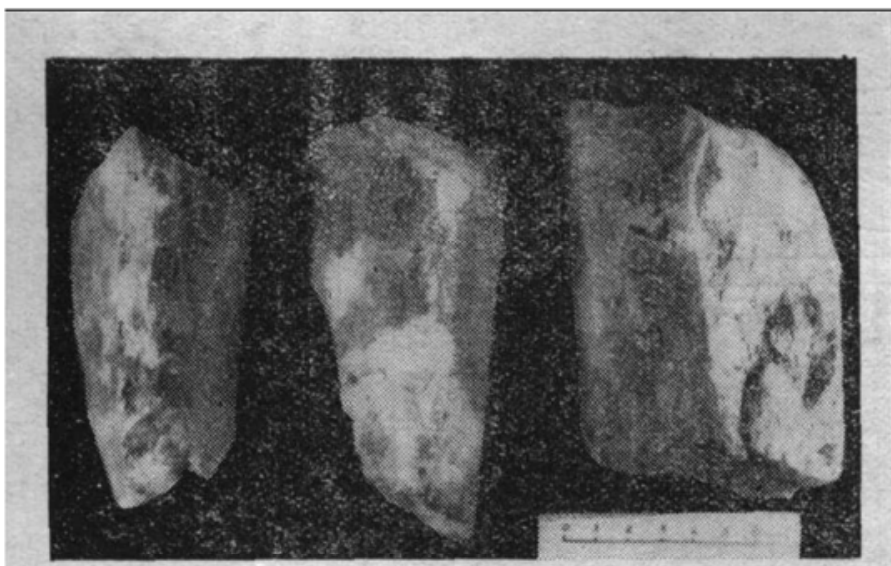

圖 3 由誘导晶面包围的伟晶个体

表現为在石英生长过程中嫚生网状的愈合裂隙; 成矿 后变化是在成矿作用基本停此以后由于构造运动及表 生風化作用所引起的。

1. 成矿时的变化: 比較明显的有两种: 致密化及 网状脉化。前者使脉石英完全成塊状結构, 很少残留 誘导晶面, 抹浊烈地混浊化, 使脉石英变成灰色或乳 白色。这种变化多發生在䆓度为 10-30 厘米的脉中。 較窅的冰多呈网状脉化，誘导晶面残余常可見到，透 明晶体为白色忿合裂隙（筧度在 0.1 毫米以下）所分 割。变化最輕溦时仅見一組或两組愈合裂隙, 剧烈时 則有三組或更多組构成网状。發生成矿时变化的原因, 可能是温度的䮑然变化，如系构造破坏所致，則脉中 其它矿物亦应發生相应的破坏作用，且后期矿化（硫 化物的充填及交代）的富集应与构造破坏程度, 即脉 石英的混浊程度相适应。如果动力作用强烈, 脉石英 会蔡生榶晶化或碎粒化作用。以上的現象仅仅局部出 現或完全不見，因此不能認为成矿时的变化系构造作 用或动力作用所致。根据苏联学者多尔果夫的实驗材 料，人工条件下使混度駽然变化，石英則形成网状收 綃裂陓，其所得到的結构与作者所見到的一致。因此 这是引起变化的最可能的原因。按照这一覌点也可介 泽为什么脉狭比較筧时常發生更为剧烈的变化。

2. 成矿后的变化: 主要是受后期的节理割切, 而 使原生生长特点模糊。主要节理方向是与脉的走向平 行，在脉的下盘特別㡎有，有时有少許錯动。这种节 理使脉石英割裂成簿板状体，可在节理面上發生再生 現象。这些再生現象的特点也可作为确定原生石英个 体太小的根据。其他垂直走向且与地面以陡角相交, 或大致与地面平行的两組节理, 也較常見。所有这些 变化都是造成石英不沿原生誘导晶面裂开的原因, 也 榓研究原生生长特点的障碍。

总上所述，該区域脉石英的原生生长結构主要是 在开誾裂隙中自由生长的平行柱状集合体。按石英个 体来說, 大部屬于伟晶結构的氾畴。由于生长时温度

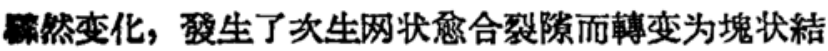

构。因此网状愈合裂隙、塊状結构仍可作为高温脙石 英的标型特征。

\section{朱而勤 ・

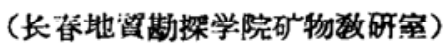 \\ 1958 年 1 月 16 日}

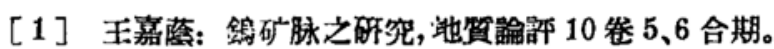

[2] Ю.А. Долгов: Гөнетическая особенность высокотөмпературных кварцев. Минералогический сборник, № 9, Львовского университета.

[3] Д.П. Григорьөв: Некоторые явления генезиса минөрал. Зап. Мин. Общ., Ц. 83, Вып 3, 1954。

\section{鷦格里沙漠包兰鉄路沿綫 中衛段固沙浩林研究 中的水分問題}

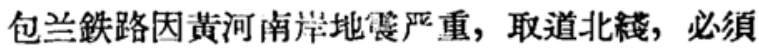
經过騰格里沙漠 40 公里。鉄路迎过沙漠的地方在甘肃 省境內, 以中衛县一段，沙沂.赽伏最大 (圖 1 ), 长达 16 公里。

在沙漠中修建鉄路在我国是一个㓣举，經过試驗 研究，鉄路由流沙上通过在工程上是可能的。問題在

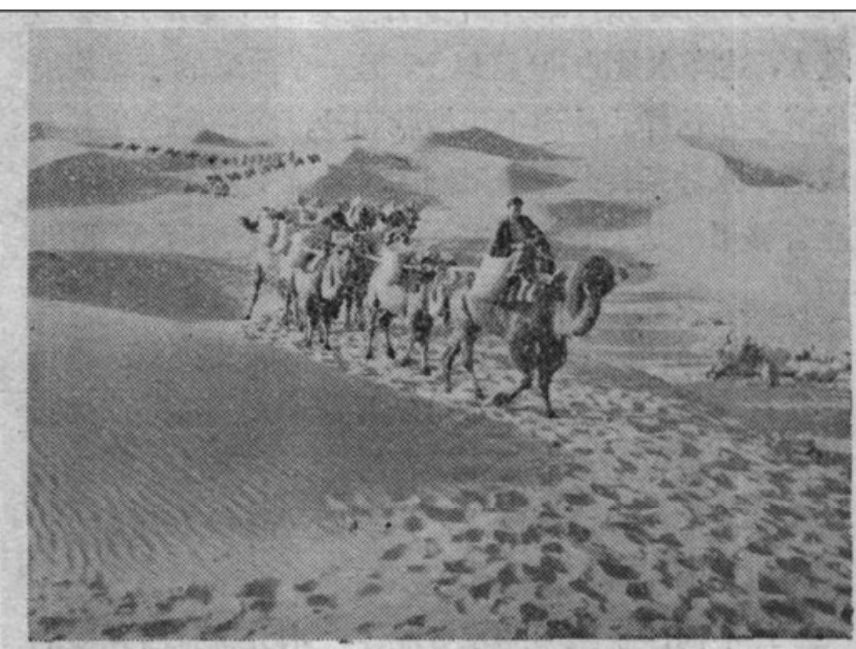

圆 1 瞗格里沙漠中衛地区格状新月形沙丘 （駱駝队为修建鉄路运鐱畉石）

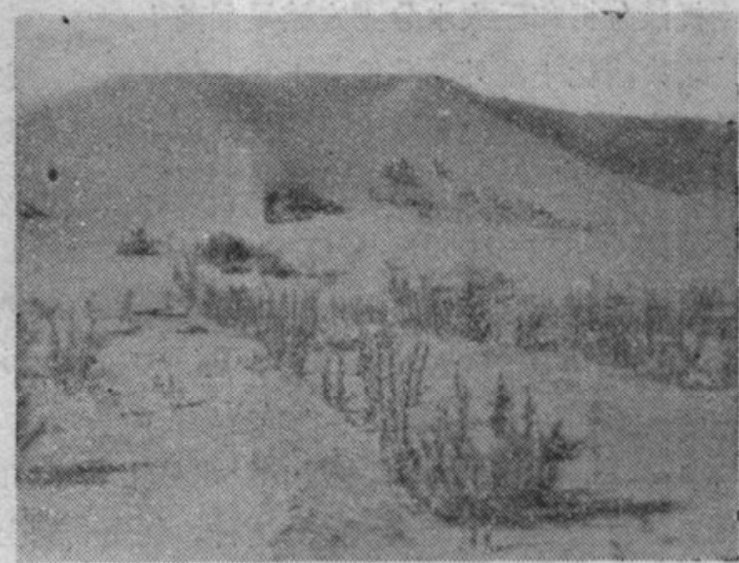

圖 2 同上, 已采取用植物固沙措施后的情况 